Kamal Prasad Acharya ${ }^{1}$

Department of Science and Environment Education, Central Department of Education, Tribhuvan University, Kathmandu Nepal
Original scientific paper

UDC: 37.018 .2

DOI: $10.5937 /$ IstrPed2002149P

\title{
SCIENCE TEACHERS' PHILOSOPHICAL THOUGHTS IN CHEMISTRY LESSONS: AN EPISTEMOLOGICAL REFLECTION
}

\begin{abstract}
The purpose of this study is to explore the epistemological foundation of science teachers' beliefs and understanding of students' activities in chemistry lessons. It also helps to find out the philosophical perspectives of science teachers and students to accomplish practical activities to transfer school science learning to activity-based instruction. Science teachers' teaching style, students' interaction and engagement in chemistry lessons and collaborative inquiry were closely observed and their epistemologies were documented and explored. Chemistry classes with practical activities were observed in two community schools located at Province 3 (Kathmandu), Nepal. Interpretive data were generated and analyzed concerning a philosophical perspective on play-way chemistry learning. The pragmatic methodological approach was applied, focusing on the experiences of students and their collaboration with the science teachers. The analysis of activity discourse showed that the learning and understanding of chemistry depend upon the basic epistemology of science teachers, activity-based learning and the collaboration between a science teacher and the students were conducted. The results suggest that the science teachers' dogmatic epistemology is the major hindrance and an influential factor resulting in students' poor understanding in chemistry lessons.
\end{abstract}

Key words: Chemistry learning, science teachers, philosophical understanding, school education, teachers' epistemology.

\section{Introduction}

The theory of knowledge about its methods, validity, scope and the difference between justified beliefs and opinions is epistemology (Ozturk, \& Yilmaz-Tuzun, 2017). To know teaching activities (pedagogical approaches) and what (content knowledge) of students' learning through practical activities in chemistry lessons are analyzed in this paper. The area of science education is related to its content knowledge and science process skills through the scientific method and its effects on society have remarkable effects. Science education is the field concerned with sharing science content and process of sharing culture and collaborative inquiry with students (Acharya, 2019). Science pedagogy is an approach to teaching, which refers to the theory and practice of learning (Pamuk, Sungur, \& Oztekin, 2017). The study aims to explore an epistemological foundation of science teachers on chemistry learning and to

\footnotetext{
1E-mail: kamalacharya@tucded.edu.np
} 
help in meaning-making of students' practices. It used an elaboration of socio-cultural perspective inspired by pragmatism (Ozturk, \& Yilmaz-Tuzun, 2017). In this article, I tried to find out how the basic epistemological framework of science teachers used to analyze to connect the relation between chemistry teaching and students' meaning-making while doing activities in chemistry lessons. It used pragmatic knowledge which focuses on blending theoretical aspects with practical activities in real teaching and learning. In the case of science teaching and learning in community schools in Nepal, knowledge of chemistry is what students know from the chalk and talk approach to teaching and what they count as relevant means of attaining knowledge (Acharya, 2019). This paper is focused on understanding how science teachers make meaning in everyday class activities in chemistry lessons and what philosophy guides them to be the teacher.

\section{Epistemological Understanding}

The meaning-making process is based on pedagogical practices of science teachers that reflect the key understanding of basic epistemological beliefs. To analyze the epistemological aspects of activities, it was important to understand the difference between philosophyblended practices and classroom learning activities. When taking terms and analytical concepts from one practice and apply them to another, it is important to consider whether this is relevant application (Watkins, Coffey, Maskiewicz, \& Hammer, 2017). Epistemological questions are the key to understand teaching and learning science at the schools in Nepal (Acharya, Acharya, \& Shrestha, 2020). The previous studies have shown that neither teachers nor students hold a unified epistemological position (Saylan, Armagan, \& Bektas, 2016). Epistemological beliefs and standpoints of teachers and students seem to be connected to specific socio-cultural situations rather than something decontextualized and universal (Soulios, \& Psillos, 2016).

Traditionally, epistemology is a thought as an enterprise which deals with questions of what makes knowledge claims valid in all circumstances (Soulios, \& Psillos, 2016). However, for pragmatists, epistemology is both a part of and a result of human practices (Bender, Schaper, Caspersen, Margaritis, \& Hubwieser, 2016). This shows that the correct way of creating reality is explored in discourses. Truth and truth making are, in this perspective, nothing mysterious, but a part of everyday life in discourse practices. If, for example, we have a theory about an experiment, the work for the philosopher is to explore the relation between the theory and activities as well as experiment. The question then is if this theory is true or false. This investigation enables me to devise a theory with the question turning up again. To understand the linkage of the wisdom and the reality, and epistemology helps to understand from the ground reality of the socially shared practices for the reproduction of truth and knowledge. To make this pragmatic view clear, I use the term practical epistemology.

\section{Epistemology of Popper and Kuhn}

Karl Popper and Thomas Kuhn attack classical positivism and its successors. Experiments and observations were the main sources of data used for scientific purposes as shown by Popper and Kuhn (Aliyu, Bello, Kasim, \& Martin, 2014). As they believe in cause and effect relationships, both Karl Popper and Thomas Kuhn agreed on: (i) view of the universe linking with the nature related to an anthropocentric lens in the service of mankind; (ii) the knowledge of falsification of the existing world view (Richards, \& Daston, 2016); (iii) the view of single reality in positivistic faith in science; and $(v)$ analytical study from the parts to the 
whole. For Popper, inductive logic (Paris, \& Vencovska, 2015) does not work if one looks at something without anticipation of what to explore. The hypothetico-deductive model (Martini, 2017) was used by Popper on the basis of progress in science.

The primary emphasis has remained on discovery by inductive-empirical processes, although Popper's influence, probably indirect and implicit, has been manifested in an increasing recognition of the theoretical aspects of science. The basic epistemology of Kuhn related to the scientific changes consists of paradigms-separated-by-revolutions and socio-psychological factors which have no more linking with the cause-and-effect relationship. The knowledge horizon of Kuhn's and his value of knowledge is not simply theory-based as related BaconianNewtonian sense, nor have they simply organized structures in the Popperian sense; rather they include theory and instruction.

\section{Methodology}

Exploration of science teachers' epistemological continuum is not new in the context of Nepal. Research shows that one of the vital issues learning the content of chemistry is based on the epistemology applied and embedded in the "pedagogical discourses" (Acharya, Budhathoki, Bjonness, \& Jolly, 2020). Studies show that students' understanding of the epistemological nature of science can influence the knowledge presented and interpreted what the teacher says and understands of the value of laboratory work (Elby, Macrander, \& Hammer, 2016). Furthermore, research also shows that epistemological commitments of science teachers influence their practices and behaviours of teaching and that many teachers' practice can be connected to the positivistic view (Glackin, 2016). Also, it has been emphasized not only examining the epistemological beliefs that teachers hold is important, but also how students perceive and conceptualize learning (Cam, Sulun, Topcu, \& Guven, 2015). These studies show that the connection between the epistemology and teaching link to the meaning-making process and subject matter learning. It may be said that the basic epistemology is an important part of discourse analysis and classroom practices. In socio-cultural perspectives, interactions and collaborative inquiry used by the students and teachers are crucial for analyzing and understanding learning. With inspiration from (Gunes, \& Bahcivan, 2018), interaction is here perceived as practice while doing experiments. Instead of following the tested body of knowledge of how students generate an association between interactions and make meanings of the world, the use of the question-answer pattern is seen as meaningful in the first phase.

Practical epistemology is used to gain knowledge about the connection between how students create meaning and what meanings they create (Tezci, Erdener, \& Atici, 2016). This type of analysis helps to identify targeted experiences and interactions important what a student learns. Applying this view, real field experiences of learning by doing in chemistry lessons are taken into account while analyzing actions in practices.

\section{Setting the Case through Practical Activities}

What I am concerned in exploration of philosophical thoughts in chemistry lessons, it is reflected that science teachers and students do practical activities through collaboration. Therefore, the strategy for selecting material was to choose a specific lesson, observed closely with the availability of limited instructional resources to perform practical activities and epistemological moves. This article is based on approximately four and a half hours (six 
classes each of 45 minutes) of observation from five classes in two community schools in 2019. I have chosen to observe practical activities from grade six, where students were 12-13 years old. Mixture separation was the study lesson through students' activities. Science teachers did not prepare for conducting practical activities; chemistry lessons follow the ordinary schedule and the teachers' design. So, two different teachers treated the chemistry course in varying manners. Chemistry classes were closely observed to identify teacher-student interactions to explore their epistemology. Of those interactions and collaborative inquiry during the four and half hours of observation, it was observed that the subject matter (content knowledge) was involved in the discussion. The school had approximately 320 students of 6-16 years from grade 1 to grade 10 . Both of the sampled schools were community schools having large catchment areas and with a diverse socio-economic status of parents. In almost all of the lessons, the science teachers started with a problem where they should use their knowledge in chemistry to find out liquids separation. There were 31 students in the sampled class; all of them did work in groups with the same assignment, with no other introduction than making experiments to find out the separation of liquids through an experiment. The teachers usually introduced every activity and the students performed experiments on the demonstration table. Only six students were performing experiments at a time and the rest of them observed and asked questions from the benches at the back of the class. Their task was related to listen to instructions given by the teacher and performing experiments in chemistry lessons.

\section{Results: Observation Epistemology in Chemistry Lessons}

In every chemistry lesson, students were separating two liquids (e.g., water and oil) through a separating funnel in the classroom. They were collecting the required materials (e.g. separating funnel, beakers, glass rod, and tripod stand) on the demonstration table in front of the class. At the beginning of the lessons, the teachers were instructing students on how to be involved in the activities. But, their priority was based on transmitting the theoretical knowledge of chemistry lessons. Students performed a series of activities and reached the conclusions. They recorded the data based on their observations and experiments. Two students were mixing water and oil in a beaker. Another two were fixing the knob of separating funnel and hold on the tripod stand. The names of the participating students are given in Annex A.

\section{Experiment $A$ (Separation of the mixture of oil and water)}

$\mathrm{B}$ (oy) S(tudent)1: I don't think we can separate two liquids by this method.

$\mathrm{G}$ (irl) S(tudent)1: You cannot.....!

BS1: No, because both liquids are transparent

GS1: One is viscous and the other is clear. But, both are translucent.

GS2: No no, one is thick and viscous. I know another is water and yes, it is transparent.

The students were talking about the mixture of two liquids and pointing towards the separating funnel. Their work was to separate both the liquids in two different beakers but since the content was unknown; there was a gap of content. To fill this gap, they started heat both the liquids in a beaker and removed the flame when they saw bubbles in the funnel. By doing this, the students started to discuss. In the discussion, I observed a gap between the teacher and the students. The students shared wrong information but it was not corrected by the teacher. To fill the gap between the knowledge of the students learned that both the students shared the common statement as 'both of the liquids are not transparent'. The initial 
gap because they could not establish a relation in terms of similarity between the density of the liquids and temperature and thus the relation established was a difference. The Students had nothing to go on at this point. The teacher was simply standing behind the classroom and observing the students' activities but he never corrected the wrong idea of mixture separation. Both of the students were guided by the science teacher in a way that the basic epistemology of the teacher in terms of scientific awareness based on the dogmatic belief of what they had learned and remembered a long ago.

Data showed different epistemological moves that the science teacher made in the context of the students' learning process. Science teachers' action in connection with hands-on activities of students in terms of the epistemological base is given in the following lines:

\section{Experiment B}

(??)When does a liquid separate?

After boiling or when the first liquid boils, it could not even measure but can be separated. Lower liquid boils, yes?

Yes, sir

And, ... second liquid?

It remained at the bottom of the vessel, sir.

Can you separate both? Please, try!

Now the lower liquid is water, and the upper one is oil

How do you know?

Nobody responded. Yes, you are correct.

(Teacher pointed out the girl and said).

This conversation and collaborative inquiry show that the science teacher lacks the concept of the liquid separation technique. He was puzzled without knowing that he did not know how density was related to the liquid separation. The

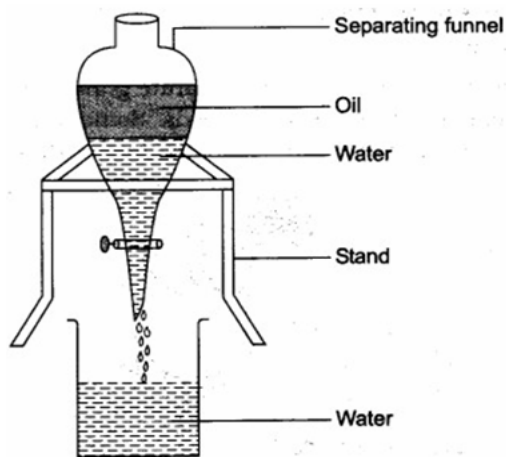

Figure 1: Liquids separation teacher's epistemology goes behind the temperature but with the density. In performing this experiment, the science teacher facilitated the students in how to put liquids in a separating funnel and the endpoint through which the two liquids separated. Now, the teacher stood on the last bench of the class and observed the students' activities. He was moving sometimes around the students' desks and interacting with the students. This process lasted for about 10 minutes to identify that two liquids boiled, so helped separating from each other. One of the girl students explained to the teacher what she had seen, and the teacher confirmed to their observation in another authorizing move. Thus, a statement about what the students were already doing could fill a confirming action. The teacher continued to ask about the second liquid. More students answered this. The teacher pointed at what the students needed to do to find the right solution. In other words, it used a move and said that there might be other properties worth investigating. 


\section{Philosophical thought implied in the Chemistry Experiment}

The students remained sitting quietly for about a minute and started conversations and collaborations:

\section{Experiment C (Separation of salt and water)}

Sir, I don't know what and how liquids

separate!

Yeah, not clear.

Sir, let's do it again or you can show to us. Liquids separated by heating. But our device (separating funnel) is not working.

What did it separate? Not visible for me.

Ha ha ... not visible means not separated yet! It did not work. We will do all these in the next class or the next year.

Based on the interactions between the students and the teacher, the students had

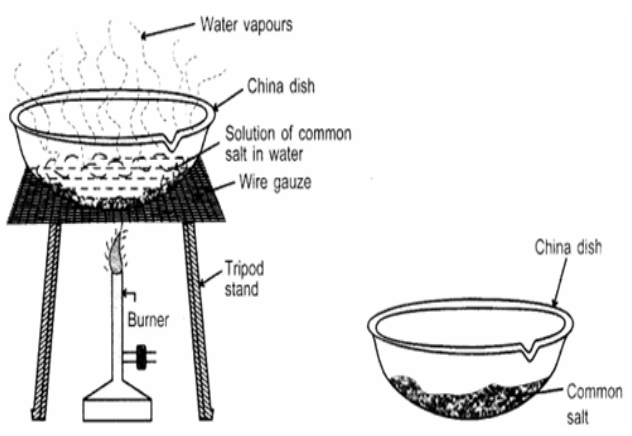

Figure 2: Separation of mixture no idea about what other properties they could check. The embedded epistemology of the science teachers was based on the dogmatic values of education: what they studied a long ago. The conversation was neither explicitly stated nor connected to the previous knowledge of the students for the meaning-making process. These students required more support than simply this sort of conversation based on the theoretical portion in practical activity. The students could not make any further relations to what kind of experiments were possible to perform for this purpose. Despite this, one of the students said that they should write down in the note copy. The students continued arguing about what to write and the only available option, water or alcohol. The teacher did not acknowledge the relationship between the density and the up-thrust of liquids which needed to know to separate liquids with the help of the separating funnel.

Similarly, in another school, the students work together with a practical assignment called mixture separation. The task of the experiment was to dissolve common salt in water and separate both the components separately. The students were supposed to make a saturated solution. The solution was first heated. Then it was supplied with heat continuously till all the water from the beaker evaporated out. In the instructions, there were questions about saturated and unsaturated solutions. The purpose of this activity is that the students shall learn about mixture separation. They poured one spoonful of common salt on little water in a beaker.

\section{Experiment D}

Four students (two girls and two boys) were ready to experiment in front of the others. They were experimenting with a demonstration table and showing to others as:

Let's see, I took little water in a beaker in which one pinch of common salt is added in it. Yes, it is visible (he was at the first bench and so he saw the salt added to water). What happens ... nothing! No no ... salt disappear. 
Yes, it is transparent.

So fast dissolve. Now, it looks like ordinary water.

Yeah.

Do you know how salt dissolves?

(Four of them respond at the same time.) Yeah. (She further elaborated as 'crystals of salt are very small as compared with other solid and so dissolve fast'.)

Sir, why water level does not rise?

Crystals disappear. But salt ions fit in the space of water molecules. Write down what you have observed.

Sir, now I understand the process by which salt dissolves in water. (She wrote the equation of dissociation on the blackboard in this way)

$A B \rightleftharpoons A++B-$

$\mathrm{NaCl}(\mathrm{s}) \rightleftharpoons \mathrm{Na}+(\mathrm{aq})+\mathrm{Cl}-(\mathrm{aq})$

The formula unit of sodium chloride $(\mathrm{NaCl})$ dissociated into sodium ion $\left(\mathrm{Na}^{+}\right)$and a chloride ion $\left(\mathrm{Cl}^{-}\right)$. She drew the equation on the blackboard showing how salt dissolves in water.

From the above interactions and experiment, it is obvious that a lot of things stand fast for the students in doing practical activities. For example, the students got the meaning of solution, dissociation, space, ions, solubility and water. None of these words was questioned, and no one hesitated using these words. A gap arose when the students could not establish any relationship between the changes of the condition and adding common salt to water and what had happened in the beaker. Student noticed during an experiment and communicated to another friend that nothing would happen (liquid level would not rise) during this experiment. The water looks as it was before.

This is in line with the methodology case, a confirming move. The students then told the teacher that the solution looked like ordinary water. Again, he stated that nothing would happen, except the salt would be invisible in water. The teacher replied with an epistemological move. The science teacher came to confirm that the students performed a perfect experiment and observation. In this situation, the teacher focused on paying attention to the facts of noticing a valid experiment. It took about ten minutes in the demonstration table to continue the practical activity to perform this experiment. After the teacher's move, the students continued with the experiment. The gaps were above even after the teacher's re-construction, since the student repeated that nothing would happen when it dissolved. The students were told what to do to be able to recognize what was worth seeing in the experiment. This we call an instructional epistemological move since the teacher gave the students a direct and concrete instruction for how to act to see what was worth noticing.

\section{Epistemological Beliefs in Practical Activities}

The basic epistemology of the school science teacher was based on cognitive knowledge even in practical activities. It is the reason why the school science teacher ignored practical activities in the daily routine. During an experiment, the focus of the teacher was on textbook recitation and the dictation of the main points. To reach, the aim and the purpose of the demonstrations and laboratory experiments, the teacher was convinced that the truth of what they were sharing and I gave examples but they didn't believe me. Without 
consideration of cognitive processes, the students were got to do practical activities but the priority of the teacher was on theoretical notes and lessons.

Overall the philosophical examination based on the epistemological orientation and its output in chemistry lessons with activities is shown in Table 1.

Table 1: Epistemological Orientation in Chemistry Lesson

\begin{tabular}{|c|c|c|}
\hline Grouping & Explanation & Epistemology in Activities \\
\hline $\begin{array}{l}\text { Exploration of } \\
\text { earning }\end{array}$ & $\begin{array}{l}\text { Conceptual knowledge } \\
\text { through hands-on activities }\end{array}$ & $\begin{array}{l}\text { Students got exploratory ideas while doing } \\
\text { activities. Teacher back up on what is written in } \\
\text { the textbook. }\end{array}$ \\
\hline $\begin{array}{l}\text { Verify the scientific } \\
\text { concept with } \\
\text { activities }\end{array}$ & $\begin{array}{l}\text { Students are attempting } \\
\text { activities to verify what is } \\
\text { written in the textbook }\end{array}$ & $\begin{array}{l}\text { Theoretical knowledge is verified while doing } \\
\text { activities in the class }\end{array}$ \\
\hline $\begin{array}{l}\text { Teachers' } \\
\text { scaffolding }\end{array}$ & $\begin{array}{l}\text { Science teacher guides } \\
\text { students from sides }\end{array}$ & $\begin{array}{l}\text { Understanding the theoretical portion through } \\
\text { practical activities }\end{array}$ \\
\hline $\begin{array}{l}\text { Students' science } \\
\text { process skills }\end{array}$ & $\begin{array}{l}\text { Students learn the ideas of } \\
\text { handling apparatus }\end{array}$ & $\begin{array}{l}\text { Learn care and handling test tubes, separating } \\
\text { funnel, beakers, spirit lamps, etc. Theoretical } \\
\text { understanding transfer into practical activities. }\end{array}$ \\
\hline
\end{tabular}

\section{Summary and Conclusions}

The science teachers in this study have shown unique beliefs and actions. Their epistemology was based on the assumption that students are consumers of science and never have to attend deeper cognitive processes involved in practical activities. Such beliefs of the science teachers were consistent with the primary teaching goals, delivering information and simply transmitting it from the teacher to the students. Their epistemological beliefs, goals, and actions were connected to dogmatic beliefs and traditions in which they believed the text but not knowledge exploration during and after the activities.

The teachers linked the beliefs of the cognitive knowledge of science contents to use of previously known facts and not on activities. Furthermore, they emphasized science as a process of problem-solving and provided the students with activities advocating the content knowledge in the textbooks rather than an exploration of new findings and challenging the situation. On the other hand, it is shown two different epistemological belief sets with different goals and actions through their statements and the ways of using laboratory activities as if they operated in two different worlds. Another student (demonstrated another level of complexity in connections with beliefs and actions. She expressed contextualism in her epistemological belief statements; faboured in multiple realities even in learning science. Also, she perceived the valid view in the context of the chemistry laboratory that never supported options for the students to evaluate multiple reasons. Instead, she aimed to help students appreciate science through direct experiences of rigorous scientific validation processes. Another student explicitly expressed that her hands-on activities only addressed rigorous validation processes following privileged ways of doing and thinking.

Even though the epistemological moves that we have identified fulfill different functions, as seen in the student-teacher interaction both in the method of teaching learning as well as the ways of expression among them, they have one common feature. All epistemological moves could thus be called attentional. The students did not learn anything in these activities from the teacher's dogmatic epistemological belief. Hence, this epistemological belief blocks the possibility for students to generate new relations out of what stands fast, in the discussion 
that they already control. A change in the students' practical epistemology, their learning of how and what to observe, is a way of getting closer to the scientific concept. Despite several interactions and $\mathrm{s}$ attempts that fill attentional functions, students expressed that nothing happens. But after iterating reminders from the teacher, students learned how to pay attention to they learn what is a valuable observation.

\section{Discussion}

This research aimed to explore the epistemology of the science teachers in chemistry lessons. For that purpose, the observed data were analyzed to explore the philosophical backups of school science teachers in the community schools in Nepal. The findings showed that the dogmatic beliefs and experiences of the science teachers were the major hindrances and obstacles to the low academic performance of the students in chemistry lessons. Science teachers theorize and apply the technique of teaching by composing their own beliefs (Taylor, \& Booth, 2015). Out of many factors identified in the literature, this study has shown that science teachers' epistemological beliefs about chemistry teaching and learning partly explain the role of practical activities to enhance the science process skills among the students. This way of using practical activities is consistent with external teaching conditions such as external tests to the extent that the teaching practice is rarely challenged (Tasquier, Levrini, \& Dillon, 2016). The cases of this study and others (Wong, \& Luft, 2015) demonstrated that science teachers' sophisticated epistemological beliefs are rarely shown in chemistry practical activities. Science teachers preferred the meaningful teaching approaches (Brownlee, Schraw, Walker, \& Ryan, 2016), but the actual classroom practices are also influenced by a variety of factors in schooling (Kampa, Neumann, Heitmann, \& Kremer, 2016; Tasquier, Levrini, \& Dillon, 2016; Wong, \& Luft, 2015). First-hand practical activities are very important for both science teachers and students for understanding the basic concepts in chemistry.

To learn scientific ways of perceiving, talking, and acting, students must change their basic epistemology into practical oriented activities and their way of privileging. In other words, they have to learn to use a new practical epistemology and it is in this process that teaching becomes important. When using different epistemological moves, the teacher interplays with the students in directing their attention to new and relevant things in the specific practice (Wong, \& Luft, 2015). Consequently, the students can create the intended scientific knowledge (Acharya, Devkota, Budhathoki, \& Bjonness, 2018). It is in this sense that one could say teaching and learning are epistemological, not necessarily in an analytical in the philosophical sense. Teaching is sometimes defined as providing opportunities to students to learn scientific concepts based on activities and collaboration. It shows that teaching is a discursive act where students' attention is directed towards certain phenomena, events, questions, gaps, and relations while others are neglected. The re-orienting move was not as successful. One reason why this move was not fruitful could be that it did not, in a direct way, connect to the meaning-making that the students were engaged in. The re-orienting move only succeeded in bringing to the students' attention that they should continue their work but in a new direction. The generative move, on the other hand, gives a specific direction, related to the students' previous meaning-making.

Moreover, for science teachers, chemistry is a body of factual knowledge to be obtained from chemical analysis and we don't need to think, change and transfer the concept. He frequently presented science as facts that focused on telling how things work (observation on the conversation). Moreover, he had not any basic epistemology of the possibility of multiple 
realities or truths in chemistry. He further said that the molecular formula of water is $\mathrm{H}_{2} \mathrm{O}$. Nobody can change it. If you desire to modify it, you are foolish. She further added that the students in chemistry lesson need to recite the molecular formula, symbols and equations. No use of practical activities in such activities. This clearly showed that his epistemological and philosophical backup is completely based on the stereotypic mode of knowledge. The generative move required that the students tried to modify their focus to the meaning-making process to do activities in chemistry lessons. Several studies have reported that science teachers often hold a positivistic view of science (Brownlee, Schraw, Tasquier, Levrini, \& Dillon, 2016; Wong, \& Luft, 2015). In the same line, Levrini, and Dillon (2016) argued that teachers' view on science can, of course, have important implications for their teaching and students' learning of science. At the same time, it is important to recognize that teachers' actions may have several other reasons, for example, to organize and manage the classroom situation (Wong, \& Luft, 2015). This further shows that we cannot take for granted that all teachers have an elaborated view of chemistry or that teacher automatically and consciously act by such a view. This means that a study of teaching and learning activities can shed light upon the collaboration between the epistemological dimensions of the teaching of how (pedagogy) and what (content) in chemistry lessons. But, it is difficult to think that exploration of beliefs and values can come up with results, can be used to predict students' activities in the classroom (Acharya, Rajbhandary, \& Acharya, 2019; Bender, Schaper, Caspersen, Margaritis, \& Hubwieser, 2016; Soulios, \& Psillos, 2016). We believe that it is both interesting and important to get an understanding of a view of chemistry interactions with students' activities and we think it can be studied through collaboration.

Another, the science teacher's teaching goals seem to be closely related to their ontological beliefs. The cases in this study show that a science teacher wants to deliver information when he/she views science as accumulative factual knowledge. This helps minimizing cognitive loads among students. Furthermore, science the teachers emphasized only the delivery of factual knowledge when they considered science as the evolving and fixed subject. The students tend to emphasize problem-solving skills associated with the process to support the observed data from an experiment. Also, the relational aspect of the science teachers' epistemological beliefs seems to guide the design of instructional activities that need to be done in the chemistry laboratory. When teachers separate students from activities, they perceive students as passive learners who are the spectators of science (Acharya, 2016; Bender, Schaper, Caspersen, Margaritis, \& Hubwieser, 2016). In contrast, when a chemistry teacher connects science to practical activities, he/she views students as small scientists who can construct meanings on their own. The teacher, therefore, tends to provide students with opportunities for doing science to have ownership of their learning. Further research with various cases will shed light on how science teachers negotiate their commitment to their epistemological beliefs with instructional goals based on chemistry lessons.

\section{Acknowledgements}

I would like to thank the students and teachers who actively participated in this study. I would like to sincerely thank the seniors, teachers and professors for motivating me for such academic work.

Any opinions, findings, and conclusions made here are those of mine and the participants do not necessarily reflect the views of the Ministry of Education (MoE), Government of Nepal. 


\section{References}

Acharya, K. P. (2016). Fostering critical thinking practices at primary science classrooms in Nepal. Research in Pedagogy, 6(2), 1-7. https://doi.org/10.17810/2015.30.

Acharya, K. P. (2019). Demystifying science teachers' epistemic belief on chemical concepts: students' engagement in the school garden. Pedagogical Research, 4(4). https://doi.org/10.29333/pr/5943.

Acharya, K. P. (2019). Participatory Action Research for Learning Chemistry: A Case of Public Schools in Nepal. Journal of Advanced College of Engineering and Management, 5, 4552. https://doi.org/10.3126/jacem.v5i0.26680.

Acharya, K. P., Acharya, M., \& Shrestha, M. K. (2020). Collaborative Learning Practices by Gender: A Case of a Community School in Nepal. International Education Studies, 13(4), 75-83. https://doi.org/10.5539/ies.v13n4p75.

Acharya, K. P., Budhathoki, C. B., Bjonness, B. \& Jolly, L. (2020). Policy perspectives on green school guidelines: connecting school science with gardens to envision a sustainable future. Journal of Sustainable Development, 13(3). https://doi.org/10.5539/jsd.v13n3p102.

Acharya, K. P., Devkota, B., Budhathoki, C. B., \& Bjonness, B. (2018). Relevance of learning science through inquiry based participatory action research in basic public schools of Nepal: A proposal. The Online Journal of New Horizons in Education, 8(4), 87-97.

Acharya, K. P., Rajbhandary, R. \& Acharya, M. (2019). (Im)Possibility of learning science through livelihoodactivities at community schools in Nepal. Asian Social Science, 15(6). https://doi.org/10.5539/ass.v15n6p88.

Aliyu, A. A., Bello, M. U., Kasim, R., \& Martin, D. (2014). Positivist and non-positivist paradigm in social science research: Conflicting paradigms or perfect partners. J. Mgmt. \& Sustainability, 4, 79. https://doi.org/10.5539/jms.v4n3p79.

Bender, E., Schaper, N., Caspersen, M. E., Margaritis, M., \& Hubwieser, P. (2016). Identifying and formulating teachers' beliefs and motivational orientations for computer science teacher education. Studies in Higher Education, 41(11), 1958-1973. https://doi.org/10.1080/03075079.2015.1004233.

Brownlee, J. L., Schraw, G., Walker, S., \& Ryan, M. (2016). Changes in preservice teachers' epistemologies. Handbook of epistemic cognition, 300-317.

Cam, A., Sulun, Y., Topcu, M. S., \& Guven, G. (2015). The Examination of Pre-Service Teachers' Epistemological Beliefs in Terms of Hofer's and Hammer \& Elby's View. ProcediaSocial and Behavioral Sciences, 182, 249-253. https://doi.org/10.1016/j.sbspro.2015.04.762.

Elby, A., Macrander, C., \& Hammer, D. (2016). Epistemic cognition in science. In Handbook of epistemic cognition (pp. 125-139). Routledge.

Glackin, M. (2016). ‘Risky fun'or 'Authentic science'? How teachers' beliefs influence their practice during a professional development programme on outdoor earning. International Journal of Science Education, 38(3), 409-433. https://doi.org/10.1080/09500693.2016.1145368. https://doi.org/10.1007/s10763-016-9761-7.

Kampa, N., Neumann, I., Heitmann, P., \& Kremer, K. (2016). Epistemological beliefs in science a person-centered approach to investigate high school students' profiles. Contemporary educational psychology, 46, 81-93. https://doi.org/10.1016/j.cedpsych.2016.04.007.

Martini, C. (2017). Hypothetico-Deductive Method. The Wiley-Blackwell Encyclopedia of Social Theory, 1-3. https://doi.org/10.1002/9781118430873.esto669. 
Ozturk, N., \& Yilmaz-Tuzun, O. (2017). Preservice science teachers' epistemological beliefs and informal reasoning regarding socioscientific issues. Research in Science Education, 47(6), 1275-1304. https://doi.org/10.1007/s11165-016-9548-4.

Pamuk, S., Sungur, S., \& Oztekin, C. (2017). A multilevel analysis of students' science achievements about their self-regulation, epistemological beliefs, learning environment perceptions, and teachers' characteristics. International Journal of Science and Mathematics Education, 15(8), 1423-1440.

Paris, J., \& Vencovska, A. (2015). Pure inductive logic. Cambridge University Press. https://doi.org/10.1017/CBO9781107326194.

Richards, R. J., \& Daston, L. (Eds.). (2016). Kuhn's' Structure of Scientific Revolutions' at Fifty: Reflections on a Science Classic. University of Chicago Press. https://doi.org/10.7208/chicago/9780226317175.001.0001.

Saylan, A., Armagan, F. O., \& Bektas, O. (2016). The Relationship between Pre-Service Science Teachers' Epistemological Beliefs and Preferences for Creating a Constructivist Learning Environment. European Journal of Science and Mathematics Education, 4(2), 251-267.

Soulios, I., \& Psillos, D. (2016). Enhancing student teachers' epistemological beliefs about models and conceptual understanding through a model-based inquiry process. International Journal of Science Education, 38(7), 1212-1233. https://doi.org/10.1080/09500693.2016.1186304.

Tasquier, G., Levrini, O., \& Dillon, J. (2016). Exploring students' epistemological knowledge of models and modelling in science: Results from a teaching/learning experience on climate change. International Journal of Science Education, 38(4), 539-563. https://doi.org/10.1080/09500693.2016.1148828.

Taylor, D. L., \& Booth, S. (2015). Secondary physical science teachers' conceptions of science teaching in a context of change. International Journal of Science Education, 37(8), 1299-1320. https://doi.org/10.1080/09500693.2015.1035356.

Tezci, E., Erdener, M. A., \& Atici, S. (2016). The Effect of Pre-Service Teachers' Epistemological Beliefs on Teaching Approaches. Universal Journal of Educational Research, 4(n12A), 205-215. https://doi.org/10.13189/ujer.2016.041326.

Watkins, J., Coffey, J. E., Maskiewicz, A. C., \& Hammer, D. (2017). An account of teachers' epistemological progress in science (pp. 89-113). Charlotte, NC: Information Age.

Wong, S. S., \& Luft, J. A. (2015). Secondary science teachers' beliefs and persistence: A longitudinal mixed-methods study. Journal of Science Teacher Education, 26(7), 619645. https://doi.org/10.1007/s10972-015-9441-4.

Annex A: Elaborated meaning of symbols used for Research Participants

\begin{tabular}{lll}
\hline Symbol & Elaborated Meaning & Students number (e. g., 1, 2. 5, 9, 11) \\
\hline SB1 & Student boy & 1 \\
SG1 & Student girl & 2 \\
ST & Science teacher & \\
S & Students & \\
\hline
\end{tabular}

\section{Biographical notes:}

Mr. Kamal Prasad Acharya is a PhD fellow of NORHED/Rupantaran project, Faculty of Education,Tribhuvan University, Nepal. He has been involving in teaching science since 2005 at secondary, higher secondary, Post Graduate Diploma, Masters and MPhil levels in the schools, 
colleges and the universities in Nepal. He was developing a number of curricula, written textbooks and reference materials for the Master's level students. He was involving a number of research projects in Nepal and abroad. He has been working as a subject expert at the National Assessment of Students' Achievement in 2008-2010, an expert of science education research conducted by UNESCO related to the cognitive development of students in Nepal. Also, his expertise reflected in a number of research projects funded by the World Bank, UNESCO, UNICEF, CERID, ERO and the Ministry of Education, Nepal. Now, he is involved in teaching and supervising the Masters' and MPhil level students, involving in science teachers professional development activities. Acharya's main research interests relate to science education in the field of teaching and learning, curriculum development, sustainable development, inquiry-based learning, participatory action research, critical thinking and transformative pedagogy. Based on these themes, Mr Acharya has published more than thirty research papers in the national and international peer-reviewed journals. Mr Acharya has taken the Teacher Preparation Programme (TPP) training at the JAMK and HAMK Universities of Applied Sciences, Finland. He was the PhD guest researcher at the Norwegian University of Life Sciences (NMBU), Norway. Currently, he is a PhD fellow under NORHED/Rupantaran project, Tribhuvan University. Following participatory action research, he is to construct a contextualized science curriculum based on activity-based learning through school gardening in Nepal. 